therapy. ${ }^{1}$ However, Potts shunt does not replace DLTx, which remains the ultimate treatment for end-stage iPAH.

Closure of the Potts shunt was mandatory before establishing CPB. Surgical techniques, such as division of the anastomosis with a separate closure of the aorta and the pulmonary artery, occlusion of the shunt with a mechanical stapler, and transpulmonary patch closure, have been associated with high morbidity and mortality. ${ }^{4,5}$ Thus, we decided to use an aortic endovascular stent graft to close anastomosis. In contrast to surgical correction, endovascular closure was easily performed under local anesthesia without increasing the length of cold ischemia or CPB. It proved to be a fast, safe, and effective minimally invasive procedure allowing DLTx in standard conditions. However, the long-term outcomes of endovascular Potts shunt closure in pediatric patients remain to be investigated.

\section{References}

1. Baruteau AE, Serraf A, Lèvy M, Petit J, Bonnet D, Jais X, et al. Potts shunt in children with idiopathic pulmonary arterial hypertension: long-term results. Ann Thorac Surg. 2012;94:817-24.

2. Toyoda Y, Thacker J, Santos R, Nguyen D, Bhama J, Bermudez C, et al. Long-term outcome of lung and heart-lung transplantation for idiopathic pulmonary arterial hypertension. Ann Thorac Surg. 2008;86:1116-22.

3. Goldstein BS, Sweet SC, Mao J, Huddleston CB, Grady RM. Lung transplantation in children with idiopathic pulmonary arterial hypertension: an 18-year experience. J Heart Lung Transplant. 2011;30:1148-52.

4. Daniel FJ, Clarke CP, Richardson JP, Westlake GW, Jones PG. An evaluation of Potts' aortopulmonary shunt for palliation of cyanotic heart disease. Thorax. 1976;31:394-7.

5. Ahmar W, Aggarwal A, Skillington P, Atkinson N. Closure of patent Potts shunt with aortic endoluminal stent graft. Cardiovasc Revasc Med. 2006;7:192-4.

\title{
Mycoplasma hominis prosthetic valve endocarditis: The value of molecular sequencing in cardiac surgery
}

\author{
Syed T. Hussain, MD, ${ }^{\mathrm{a}}$ Steven M. Gordon, MD, ${ }^{\mathrm{b}}$ Carmela D. Tan, MD,${ }^{\mathrm{c}}$ and Nicholas G. Smedira, MD, ${ }^{\mathrm{a}}$ \\ Cleveland, Ohio
}

Mycoplasma hominis is part of the human microbial flora of the genitourinary and respiratory tracts, but it is also an extremely rare cause of endocarditis. We report a case of prosthetic valve endocarditis caused by $M$ hominis in which the correct diagnosis was made by molecular sequencing of explanted valve tissue in response to a high index of suspicion of an infectious process arising from intraoperative findings despite negative results of routine cultures.

\section{CLINICAL SUMMARY}

A 57-year-old man had undergone aortic valve replacement with a 19-mm bioprosthetic valve, pericardial patch aortic root enlargement, and decalcification of the anterior mitral valve leaflet in October 2011 at an outside hospital. He started having increasing shortness of breath, fatigue, and intermittent chest pain 4 to 5 months after

\footnotetext{
From the Department of Cardiothoracic Surgery, ${ }^{\mathrm{a}}$ Heart and Vascular Institute, the Department of Internal Medicine and Infectious Disease, ${ }^{b}$ Medicine Institute, and the Department of Anatomic Pathology, ${ }^{c}$ Laboratory Medicine Institute, Cleveland Clinic, Cleveland, Ohio.

Disclosures: Authors have nothing to disclose with regard to commercial support.

Received for publication March 19, 2013; accepted for publication March 25, 2013; available ahead of print May 3, 2013.

Address for reprints: Nicholas G. Smedira, MD, Cleveland Clinic, 9500 Euclid Ave, Desk J4-1, Cleveland, OH 44195 (E-mail: smidern@ccf.org).

J Thorac Cardiovasc Surg 2013;146:e7-9

$0022-5223 / \$ 36.00$

Copyright (c) 2013 by The American Association for Thoracic Surgery

http://dx.doi.org/10.1016/j.jtcvs.2013.03.039
}

surgery. The cardiovascular evaluation performed at that time was unremarkable. He then was seen about 1 year after operation with a near-syncopal event. An echocardiogram showed that the aortic prosthetic valve had a peak gradient of $104 \mathrm{~mm} \mathrm{Hg}$. His coronary angiogram appeared normal. A computed tomographic scan was suggestive of a subvalvular obstruction of unclear etiology. At that time, his appetite had deteriorated, and he had lost about $14 \mathrm{~kg}$ during the previous few months, but he had no fever or chills. Routine blood cultures yielded negative results.

On the basis of these findings, the patient underwent a cardiac reoperation in November 2012. Intraoperatively, no purulence was found, although there was some fibrinoid material on the aortic prosthesis. One of the prosthetic cusps had torn from the commissure, resulting in aortic regurgitation. After removal of just a few aortic prosthesis sutures, the entire prosthesis came off easily, highly suggestive of infectious endocarditis (IE). There was also subvalvular stenosis that was not removable by forceps; it had to be cut out with a scalpel and was thus not consistent with a vegetation. There was no evidence of an aortic root abscess. The aortic root was replaced with a size 18 aortic allograft.

Because of a high index of suspicion of IE related to the operative findings, the bioprosthetic valve specimen was sent to both microbiology and surgical pathology laboratories according to our protocol. Results of routine valve cultures were negative. Histopathologic examination of the 

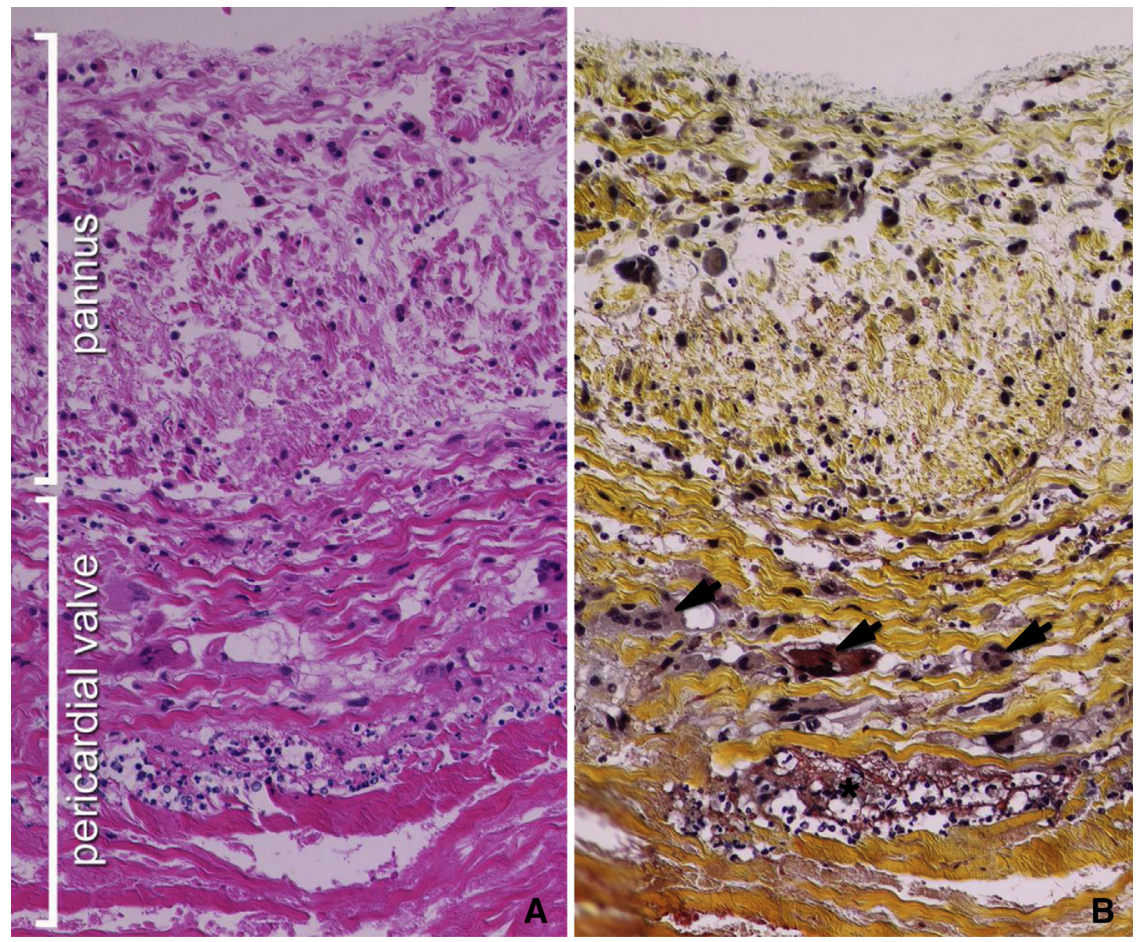

FIGURE 1. In specimens stained with hematoxylin-eosin (A) and Movat pentachrome (B), the laminated wavy collagen of the bovine pericardial tissue valve, delineated by the bracket in the lower half of the images, is infiltrated by neutrophils (asterisk), with scattered multinucleated giant cells (arrows). The overlying pannus shown on the upper half is also infiltrated with neutrophils, lymphocytes, and macrophages. No microorganisms were identified with Gram, Gomori methenamine silver, or periodic acid-Schiff stains. (Original magnification $200 \times$.)

prosthetic valve showed a thin layer of fibrinoid exudate and mild pannus formation with acute and chronic inflammatory cells, as well as multinucleated giant cells (Figure 1). The presence of neutrophilic infiltrates was highly suggestive of IE. A tissue sample from the valve was also sent for broad-range $16 \mathrm{~S}$ gene sequencing for detection of microbial DNA; it came back positive for $M$ hominis. On the basis of this diagnosis, the patient's antibiotic regimen was changed from intravenous vancomycin and ceftriaxone to intravenous doxycycline hyclate, followed by oral moxifloxacin hydrochloride (INN moxifloxacin). His postoperative course was uneventful, and he was doing well at home at 3-month follow-up.

\section{DISCUSSION}

Mycoplasma is a rare cause of IE, with only 10 cases described in the literature ${ }^{1-5}$ and only 7 of these caused by $M$ hominis. ${ }^{5}$ Most of the affected patients had undergone a previous cardiac operation, suggesting a predilection toward prosthetic valve endocarditis. In a review of 348 cases of blood culture-negative endocarditis in a reference center, Houpikian and Raoult ${ }^{4}$ found only a single case of IE caused by Mycoplasma.

Mycoplasma IE is difficult to diagnose, because these bacteria are not seen on Gram stain and are not easily grown in routine culture systems. $M$ hominis does not grow on commercial blood culture solutions that use polyanethol sulfonate as an anticoagulant but rather requires special methods for growth. Broad-range polymerase chain reaction analysis targeting the $16 \mathrm{~S}$ ribosomal DNA sequence in cardiac valve tissue specimens is an important tool for diagnosing Mycoplasma IE. ${ }^{3,4}$ An added advantage of this approach is that almost all types of bacteria can be detected with a single examination, avoiding limitations of bacterial culture. Since 2009, we have used sequencing as a tool for pathogen identification in culture-negative cases of surgically detected IE.

Although Mycoplasma IE is rare, its clinical course is not benign. ${ }^{2}$ In addition, cases of culture-negative endocarditis are not routinely investigated for Mycoplasma, so it is highly likely that these organisms' role in endocarditis is underestimated. The correct diagnosis of Mycoplasma infection is critical, because the empirical antibiotic regimen for IE of unknown etiology, consisting of a $\beta$-lactam and an aminoglycoside, is not effective. $M$ hominis is resistant to penicillinlike drugs and erythromycin, and therapy with doxycycline is the treatment of choice.

In conclusion, valve polymerase chain reaction adds substantially to the etiologic diagnosis of IE, leading 
to institution of appropriate antibiotic therapy. It should be considered in all cases in which routine cultures are negative despite a high index of clinical suspicion of IE.

\section{References}

1. Cohen JI, Sloss LJ, Kundsin R, Golightly L. Prosthetic valve endocarditis caused by Mycoplasma hominis. Am J Med. 1989;86(6 Pt 2):819-21.
2. Blasco M, Torres L, Marco ML, Moles B, Villuendas MC, García Moya JB. Prosthetic valve endocarditis caused by Mycoplasma hominis. Eur J Clin Microbiol Infect Dis. 2000;19:638-40.

3. Fenollar F, Gaudochon V, Casalta JP, Lepidi H, Vandenesch F, Raoult D. Mycoplasma endocarditis: two case reports and a review. Clin Infect Dis. 2004;38:e21-4.

4. Houpikian P, Raoult D. Blood culture-negative endocarditis in a reference center: etiologic diagnosis of 348 cases. Medicine (Baltimore). 2005;84:162-73.

5. Jamil HA, Sandoe JA, Gascoyne-Binzi D, Chalker VJ, Simms AD, Munsch CM, et al. Late-onset prosthetic valve endocarditis caused by Mycoplasma hominis, diagnosed using broad-range bacterial PCR. J Med Microbiol. 2012;61(Pt 2):300-1. 